\title{
Medical Image of the Week: Panlobular Emphysema
}

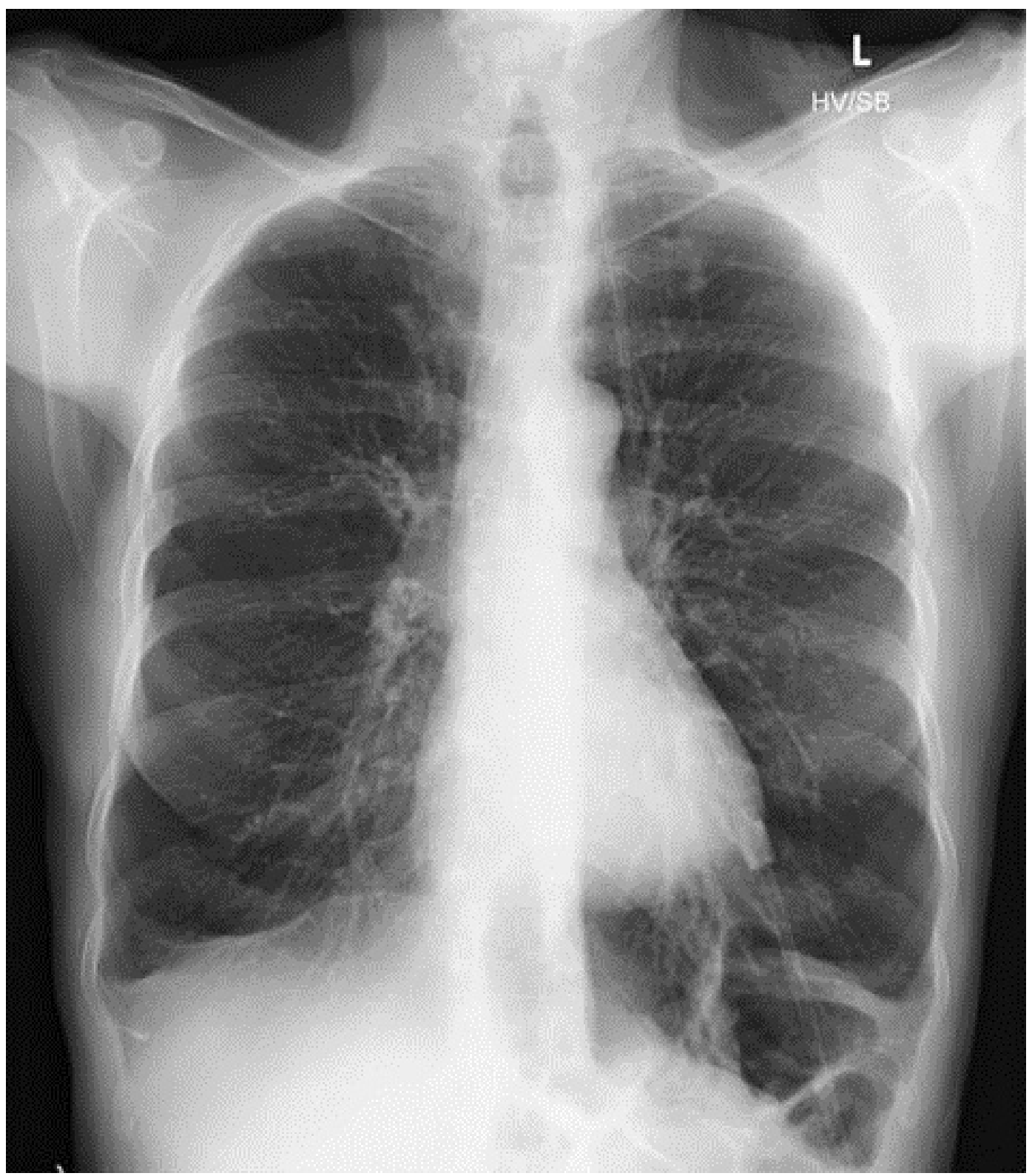

Figure 1. PA chest radiograph showing predominately lower lobe emphysematous changes.

A 60 year old female, non-smoker with a past medical history of chronic rhinosinusitis with nasal polyps presented with an eight year history of productive cough and dyspnea. Previous treatment with inhaled corticosteroids, courses of systemic corticosteroids and antibiotics provided modest improvement in her symptoms. Pulmonary function testing revealed a severe obstructive ventilatory defect without significant bronchodilator response and reduced diffusing capacity (DLCO). Chest $x$-ray surprisingly revealed lower lobe predominant emphysematous changes (Figure 1). Alpha-1-antitrypsin level was within normal range at $137 \mathrm{mg} / \mathrm{dL}$. 
Panlobular emphysema represents permanent destruction of the entire acinus distal to the respiratory bronchioles and is more likely to affect the lower lobes compared to centrilobular emphysema (1). Panlobular emphysema is associated with alpha-1antitrypsin deficiency, intravenous drug abuse specifically with methylphenidate and methadone, Swyer-James syndrome, and obliterative bronchiolitis. Whether this pattern is seen as part of normal senescence in non-smoking individuals remains controversial (2). Panlobular emphysema may represent a phenotypically more severe disease than centrilobular emphysema and may coexist along a continuum with centrilobular emphysema (3).

Ashish Mathur MD and Tara Carr MD

Division of Pulmonary, Allergy, Critical Care and Sleep Medicine University of Arizona College of Medicine Tucson, Arizona

\section{References}

1. Litmanovich D, Boiselle PM, Bankier AA. CT of pulmonary emphysema-current status, challenges, and future directions. Eur Radiol. 2009;19(3): 537-51. [CrossRef] [PubMed]

2. Takahashi M, Fukuoka J, Nitta $\mathrm{N}$ et al. Imaging of pulmonary emphysema: a pictorial review. Int J Chron Obstruct Pulmon Dis. 2008;3(2):193-204. [PubMed]

3. Finkelstein R, Ma HD, Ghezzo H, Whittaker K, Fraser RS, Cosio MG. Morphometry of small airways in smokers and its relationship to emphysema type and hyperresponsiveness. Am J Respir Crit Care Med. 1995;152(1):267-76. [CrossRef] [PubMed] 